\title{
Influence of Component Temperature Derivation from Dual Angle Thermal Infrared Observations on TSEB Flux Estimates Over an Irrigated Vineyard
}

\author{
Ana ANDREU ${ }^{1}$, Wim J. TIMMERMANS ${ }^{2}$, Drazen SKOKOVIC ${ }^{3}$, \\ and Maria P. GONZALEZ-DUGO ${ }^{4}$ \\ ${ }^{1}$ Instituto de Investigación y Formación Agraria y Pesquera (IFAPA), \\ Cordoba, Spain; e-mail: ana.andreu.mendez@juntadeandalucia.es
}

${ }^{2}$ University of Twente, Faculty of Geo-information Science and Earth Observation,

Department of Water Resources, Enschede, The Netherlands;

e-mail:w.j.timmermans@utwente.nl

${ }^{3}$ Global Change Unit (GCU), Department of Earth Physics, University of Valencia, Valencia, Spain; e-mail: drazen.skokovic@uv.es

${ }^{4}$ Instituto de Investigación y Formación Agraria y Pesquera (IFAPA),

Cordoba, Spain; e-mail: mariap.gonzalez.d@juntadeandalucia.es

\section{Abstract}

A two-source model for deriving surface energy fluxes and their soil and canopy components was evaluated using multi-angle airborne observations. In the original formulation (TSEB1), a single temperature observation, Priestley-Taylor parameterization and the vegetation fraction are used to derive the component fluxes. When temperature observations are made from different angles, soil and canopy temperatures can be extracted directly. Two dual angle model versions are compared versus TSEB1: one incorporating the Priestley-Taylor parameterization (TSEB2I) and one using the component temperatures directly (TSEB2D), for which data from airborne campaigns over an agricultural area in Spain are used. Validation of TSEB1 versus ground measurements showed RMSD values of 28 and $10 \mathrm{Wm}^{-2}$ for sensible and latent heat

Ownership: Institute of Geophysics, Polish Academy of Sciences;

(C) 2015 Andreu et al. This is an open access article distributed under the Creative Commons Attribution-NonCommercial-NoDerivs license,

http://creativecommons.org/licenses/by-nc-nd/3.0/. 
fluxes, respectively. Reasonable agreement between TSEB1 and TSEB2I was found, but a rather low correlation between TSEB1 and TSEB2D was observed. The TSEB2D estimates appear to be more realistic under the given conditions.

Key words: Two Source Energy Balance (TSEB) model, component temperatures, resistance schemes, available energy.

\section{INTRODUCTION}

Quantification of the spatial and temporal variability in hydrological processes and land surface states is of interest on several different disciplines, including agriculture, hydrology, meteorology and climatology. Interconnections and feedbacks between hydrological variables and regional hydrometeorology have led to an increase in the use of satellite remote sensing to determine the water and energy budgets at the Earth's surface. The partitioning of available energy into sensible and latent heat fluxes largely depends on the composition of the observed area, specifically, whether it is vegetated or bare. Due to the heterogeneity of the Earth's surface at most scales, energybalance models that distinguish between soil/substrate and vegetation contributions to the radiative temperature and radiation/turbulent fluxes have proven to be among the most reliable. A proper partitioning in component fluxes is of importance, not only for its practical consequences, such as the determination of the water-use efficiency of plants, but also because it is important for climate change issues, since the transpiration component shows a strong correlation with carbon sequestration (Scott et al. 2006).

During the last few decades, these physically based models have evolved in a quasi-operational mode. In particular, the Two Source Energy Balance model (TSEB) of Norman et al. (1995) has been shown to be robust for semi-arid sparse canopy-cover landscapes. Although it is physically based, still a number of assumptions and tabulated input parameters, which are neither easily available nor easily measurable operationally, and their influence on model output over a variety of landcover units need to be evaluated. Such models tend to use resistance schemes in which the turbulent sensible (latent) heat fluxes are determined by the ratio of a temperature (vapor pressure) difference between the overlaying air and the surface, whether soil or canopy, over an aerodynamic resistance to heat (vapor) transport. Since operational remote-sensing observations of vapor pressure are not readily available, the models are usually designed to utilize observations of temperature rather than of vapor pressure. As a result, these resistance schemes are used to derive sensible heat fluxes after which latent heat fluxes are then calculated as a rest-term in the energy balance. In an operational mode, the soil surface temperature, $T_{S}$, and canopy temperature, $T_{C}$, are usually derived from a single observation of directional radiometric temperature, $T_{R}$, in com- 
bination with an estimate of the fractional vegetation cover, $f_{C}$, at sensor view angle.

In the TSEB model, $T_{R}$ is calculated from the brightness temperature, which is directly measured by the radiometer, thereby assuming a single directional emissivity that represents soil and vegetation combined. Deriving the soil and canopy component temperatures from $f_{C}$ and a single $T_{R}$ observation requires an iterative process, where it is uncertain whether the proper solution is obtained in terms of component temperatures and hence in terms of properly parameterized resistances. Numerous validation studies have shown a good performance of the TSEB model flux output versus flux observations (French et al. 2005, Gonzalez-Dugo et al. 2009, Kustas and Norman 1997, Timmermans et al. 2007), which are usually "lumped-together" observations of total $H$ and $L E$ fluxes. Less is known about the validity of the internal model parameters, these being the component temperatures, resistances, and the component flux output. This limits our understanding of the physical processes involved and thus limits model portability (Colaizzi et al. 2012a, Kalma et al. 2008).

However, when $T_{R}$ observations made from multiple angles are available, the component temperatures can be derived directly (Kustas and Norman 1997), thereby offering the possibility to assess the validity of the parameterizations used. Some studies have tested the TSEB model by using component temperatures (Colaizzi et al. 2012a, Kustas and Norman 1997, Morillas et al. 2013). However, a key assumption of the TSEB model and also of other dual source models, is that the effective source/sink for turbulent flux exchange for the entire canopy, as well as for the soil/substrate, can be described by a bulk canopy, or bulk soil/substrate, temperature, and resistance (Colaizzi et al. 2012a). Even so, large local differences in observed temperature exist for sunlit and shaded leaves and soil, old and young leaves, and transpiring and non-transpiring leaves (Timmermans J. et al. 2008). When locally measured component temperatures such as in Colaizzi et al. (2012a) or Morillas et al. (2013), or ground-based multiple viewing angle observations such as in Kustas and Norman (1997) are used, they may not represent the bulk canopy and bulk soil temperatures used in the parameterization scheme. Moreover, a significant mismatch between the spatial resolution of the temperature measurements and the size of the flux footprint can cause significant discrepancies between modeled and measured fluxes (Kustas and Norman 1997). Therefore, in the current contribution we preferred to use airborne imagery acquired from viewing angles that differ more than $45^{\circ}$ at a resolution that is low enough to obtain "observations" of the representative bulk component temperatures but high enough to capture within-field variation. As such, this study focuses more on inter-model output differences than on absolute validation. 
The objective of this study was to determine how physically based retrieval of the representative bulk soil and canopy component temperatures, which are used in the model parameterization, influences estimates of the turbulent fluxes, their components, and model parameters. Thereto, first the performance of the TSEB model as it is commonly used (Anderson et al. 1997, French et al. 2005, Norman et al. 1995) is shown against ground-truth observations of radiation and energy fluxes over the current area. Then soil and canopy component temperatures from dual angle airborne observations were used in dual angle versions of TSEB (Colaizzi et al. 2012a, Kustas and Norman 1997). A comparison of the output produced by the different versions of the model is made, followed by a discussion thereof.

\section{METHODS AND MATERIALS}

\subsection{Methods}

The dual-source model used in this study is the well-established Two-Source Energy Balance (TSEB) model of Norman et al. (1995) which has shown good performance over a wide range of arid and partially-vegetated landscapes (French et al. 2005, Gonzalez-Dugo et al. 2009, Kustas and Norman 1997, Timmermans et al. 2007). Under such circumstances, a dual source model that distinguishes between the soil and vegetation contribution to the turbulent fluxes has clear and well-known advantages over simpler singlesource models that treat these contributions in a lumped manner (Huntingford et al. 1995, Kustas et al. 1996). The TSEB model presents two different versions, according to the assumed resistance network for parameterizing the energy flux exchange, being either in series or in parallel (Norman et al. 1995). The series version of the TSEB resistance network allows interactions between soil/substrate and main canopy layer and is therefore particularly useful over relatively dry but relatively densely vegetated areas. Because the vineyard area under study is characterized by just these conditions, use here is made of the series approach only. Although descriptions of the model are available in Norman et al. (1995) and Kustas and Norman (1997), the following sections offer a detailed description of the several steps involved in the different versions. This is considered relevant in view of the specific differences in their output, see Section 3.2.

\subsubsection{Single-angle model}

The single-angle model is the updated version of the Two-Source Energy Balance (TSEB) model (Norman et al. 1995), as described by Kustas and Norman (1999) and Li et al. (2005). From here on, this scheme will be referred to as TSEB1. 
The model assumes that the surface radiometric temperature $\left(T_{R}\right)$ is a combination of soil $\left(T_{S}\right)$ and canopy $\left(T_{C}\right)$ temperatures, weighted by the vegetation fraction $\left(f_{C}\right)$ :

$$
T_{R}(\varphi)=\left[f_{C}(\varphi) T_{C}^{4}+\left(1-f_{C}(\varphi)\right) T_{S}^{4}\right]^{(1 / 4)},
$$

where $f_{C}$ is affected by the sensor viewing angle $(\varphi)$. Note that the angular variation of directional emissivity is neglected because variations of less than 0.005 are obtained between viewing angles at nadir and $60^{\circ}$ for most vegetated surfaces (Anton and Ross 1987, Kustas and Norman 1997).

Because of the significance in the current study of the vegetation characteristics as seen from different angles we will describe the determination thereof in a bit more detail at this point. The method used to derive the fractional cover at nadir $(\varphi=0)$ follows from Choudhury et al. (1994), using a scaled Normalized Difference Vegetation Index (NDVI):

$$
f_{C}(0)=1-\left(\frac{\mathrm{NDVI}_{\max }-\mathrm{NDVI}}{\mathrm{NDVI}_{\max }-\mathrm{NDVI}_{\min }}\right)^{p},
$$

where $\mathrm{NDVI}_{\max }$ and $\mathrm{NDVI}_{\min }$ represent a surface fully covered by vegetation and completely bare, respectively. Parameter $p$ is the ratio of the leaf angle distribution factor, $\Lambda$, to the canopy extinction factor, $\kappa$, which is dependent on solar zenith angle $\psi$ (Campbell and Norman 1998). The apparent fractional vegetation cover at viewing angle $\varphi$ is then obtained by dividing $f_{C}(0)$ by the cosine of the sensor viewing angle. The Leaf Area Index (LAI), which is used in the estimation of extinction of net radiation and wind speed within the canopy, is related to $f_{C}(\varphi)$, following Choudhury (1987):

$$
\mathrm{LAI}=\frac{1-f_{C}(\phi)}{\Lambda} .
$$

In the case of clumped canopies with partial vegetation cover, such as vineyards and orchards, LAI is multiplied by the so-called clumping factor, $\Omega(\psi)$, which depends on solar zenith angle and vegetation structure. This factor corrects for the reduction in the extinction of the radiation in a clumped canopy as compared to a uniformly distributed one, by multiplying the LAI by the clumping factor. Here we have followed the approach suggested in Kustas and Norman (2000), following:

$$
\Omega(\psi)=\frac{\Omega(0)}{\Omega(0)+(1-\Omega(0)) \cdot \exp \left(-2.2 \psi^{P}\right)},
$$

where $\Omega(0)$ is the clumping factor at nadir viewing angle, and $P=$ $3.8-0.46 D$, where $D$ is the ratio of vegetation height to width of the clumps. 
The surface energy-balance equation can be formulated for the entire soil-canopy-atmosphere system or for the soil and canopy components separately:

$$
\begin{gathered}
R n_{C}=L E_{C}+H_{C}, \\
R n_{S}=L E_{S}+H_{S}+G .
\end{gathered}
$$

The partitioning of net radiation, $R n$, can be either directly on global $R n$ (Norman et al. 1995), or by formulations for the transmission of direct and diffuse shortwave radiation and for the transmission of longwave radiation through the canopy, as described in Kustas and Norman (1999). In the current contribution we have used the original model description following Norman et al. (1995). The spatial variation in the horizontal direction is mainly regulated by fractional vegetation cover and in the vertical (radiation extinction within the canopy) by LAI. Since the radiation formulation follows the so-called "layer-approach" (Lhomme and Chehbouni 1999), a simple summation of the soil and canopy components then yields the total of the flux under consideration.

The soil heat flux is then estimated as a time-dependent function of the net radiation reaching the soil:

$$
G=c_{g} R n_{S},
$$

where $c_{g}$ is slightly variable with time. Details of the original determination can be found in (Kustas et al. 1998). Here it is calibrated against local observations using the measurements from the test sites.

Within the series resistance scheme, the sensible heat fluxes $H_{C}, H_{S}$, and $H$ are expressed as:

$$
\begin{gathered}
H_{C}=\rho_{a} C_{p}\left(T_{C}-T_{A C}\right) / R_{X}, \\
H_{S}=\rho_{a} C_{p}\left(T_{S}-T_{A C}\right) / R_{S}, \\
H=H_{C}+H_{S}=\rho_{a} C_{p}\left(T_{A C}-T_{A}\right) / R_{A},
\end{gathered}
$$

where $\rho_{a}$ is the air density $\left[\mathrm{kg} \mathrm{m}^{-3}\right], C_{p}$ the air specific heat $\left[\mathrm{J} \mathrm{kg}^{-1} \mathrm{~K}^{-1}\right], T_{A C}$ is the air temperature in the canopy-air space $[\mathrm{K}], R_{X}$ is the resistance to heat flow of the vegetation leaf boundary layer $\left[\mathrm{s} \mathrm{m}^{-1}\right], R_{S}$ is the resistance to the heat flow in the boundary layer above the soil $\left[\mathrm{s} \mathrm{m}^{-1}\right], R_{A}$ is the aerodynamic resistance $\left[\mathrm{s} \mathrm{m}^{-1}\right]$ calculated from the stability-corrected temperature-profile equations (Brutsaert 1982) using Monin-Obhukov Similarity Theory (MOST), and $T_{A}$ is the air temperature. The procedures to derive $T_{A C}$ as well as the resistance terms $R_{X}$ and $R_{S}$ are provided in the Appendix of Norman et al. (1995), where the main inputs are wind speed, $u\left[\mathrm{~m} \mathrm{~s}^{-1}\right]$, the displacement 
height, $d_{0}[\mathrm{~m}]$, and roughness length for momentum and heat transport, $z_{0 M}$ $[\mathrm{m}]$ and $z_{0 H}[\mathrm{~m}]$, respectively. The latter three are estimated following the procedure as described by Massman and Weil (1999).

When estimates of the sensible heat fluxes $\left(H_{C}\right.$ and $\left.H_{S}\right)$ are known, the latent heat fluxes can be estimated as a rest-term from Eqs. 5 and 6. However, when a radiometric temperature image is available at only one viewing angle, an extra equation is needed in addition to Eq. 1 to solve for $T_{C}$ and $T_{S}$. In the TSEB1 formulation, following Norman et al. (1995), this is solved by deriving the canopy latent heat flux using as an initial assumption a potentially transpiring canopy, following the Priestley-Taylor equation (Priestley and Taylor 1972):

$$
L E_{C}=\alpha_{\mathrm{PT}} f_{g}\left(\frac{\Delta}{\Delta+\gamma}\right) R n_{C},
$$

where $\alpha_{\mathrm{PT}}$ is the Priestley-Taylor coefficient, usually taken as $1.26[-], f_{g}$ is the green vegetation fraction $[-], \Delta$ is the slope of the saturation vapor pressure versus temperature $\left[\mathrm{kPa} \cdot \mathrm{K}^{-1}\right]$, and $\gamma$ is the psychrometric constant $\left[\mathrm{kPa} \cdot \mathrm{K}^{-1}\right]$.

In practice, all conductive fluxes, i.e., $R n, R n_{C}, \mathrm{Rn}_{\mathrm{S}}$, and $G$, are calculated once, following the formulations as given by Norman et al. (1995), and remain constant thereafter. Then, the next step is to derive $H_{C}$ from Eq. 5 . A first approximation of $T_{C}$, i.e., the average of air temperature $T_{A}$ and radiometric temperature $T_{R}$, is used to derive $T_{S}$ from Eq. 1 . In the series approach, which was used here, a linear approximation of $T_{C}$ is calculated following the procedure described in the Appendix of Norman et al. (1995), using $H_{C}$ and $T_{S}$ to arrive at the within-canopy air temperature, $T_{A C}$. $T_{A C}$ is then used for a first estimation of $H_{S}$ using Eq. 9. $L E_{S}$ is finally derived from Eq. 6. If the vegetation is stressed, the Priestley-Taylor approximation, i.e., Eq. 11, overestimates the transpiration of the canopy and negative values of $L E_{S}$ are computed. This improbable condensation over the soil during daytime indicates the existence of vegetation water stress and it is solved by reducing $\alpha_{\mathrm{PT}}$. An updated, lower, estimate of $L E_{C}$ is obtained which yields an updated, higher, estimate of $H_{C}$ through the use of Eq. 5. Next, Eq. 8 provides a new, higher, estimate of $T_{C}$, which in turn yields a lower estimate of $T_{S}$ through Eq. 1, resulting in a lower, updated estimate of $H_{S}$. Through the use of Eq. 6 an updated, higher estimate of $L E_{S}$ is obtained. This iteration process is continued until $L E_{S}>0$.

At this moment, all the fluxes, radiative, conductive and turbulent, and their components, soil and canopy are known, as well as the "equilibrium" soil and canopy component temperatures. However, when multiple viewing angle observations of $T_{R}$ are available, the soil and canopy temperatures may 
be derived directly from the observations. These provide the opportunity to estimate the component sensible heat fluxes from Eqs. 8 and 9, thereby avoiding the need of the above iteration process and as such a check on the physical realism of the model.

\subsubsection{Dual-angle model}

In the dual-angle approach, a version also described by Kustas and Norman (1997), $T_{R}$ observations at different viewing angles provide soil and canopy component temperatures. The physical framework of the model remains identical to the single-angle version of TSEB. However, the mathematical framework to determine the turbulent fluxes is slightly different.

The soil and canopy component temperatures were obtained from the simultaneous solution of two equations containing two unknowns, where $f_{C 1}$ and $f_{C 2}$ and $T_{R}\left(\varphi_{1}\right)$ and $T_{R}\left(\varphi_{2}\right)$ are the fractional covers and the radiometric surface temperatures at the first viewing angle, $\varphi_{1}$, and second viewing angle, $\varphi_{2}$. Equation 1 was used for the two flight lines to derive the component soil and canopy temperatures, following:

$$
\begin{gathered}
T_{S}=\left(\frac{f_{C 2} T_{R}^{4}\left(\varphi_{1}\right)-f_{C 1} T_{R}^{4}\left(\varphi_{2}\right)}{f_{C 2}-f_{C 1}}\right)^{(1 / 4)}, \\
T_{C}=\left(\frac{T_{R}^{4}\left(\varphi_{1}\right)-\left(1-f_{C 1}\right) T_{S}^{4}}{f_{C 1}}\right)^{(1 / 4)} .
\end{gathered}
$$

The radiative and conductive fluxes, $R n_{S}, R n_{C}$, and $G$, are estimated following the same parameterization as in TSEB1 and they remain constant during the steps necessary to derive the component turbulent fluxes. Still, different approaches can be followed to arrive at $H_{S}, H_{C}, L E_{S}$, and $L E_{C}$. Two fundamentally different approaches are described in detail in the following sections.

\section{Dual-angle iteration approach}

In what is referred to as the dual-angle iteration approach, TSEB2I, the first step concerns the estimation of $L E_{C}$ and $H_{C}$ following Eqs. 11 and 5 as in TSEB1. $H_{C}$ is used in combination with $T_{C}$ to obtain the within-canopy temperature, $T_{A C}$, as in TSEB1. Since $T_{S}$ is known from the observations, it is used with $T_{A C}$ in Eq. 9 to estimate $H_{S} . L E_{S}$ is then calculated as a rest-term from Eq. 6. If negative values of $L E_{S}$ are computed, this problem is solved by reducing $\alpha_{\mathrm{PT}}$, as in TSEB1. An updated, lower, estimate of $L E_{C}$ is obtained which yields an updated, higher, estimate of $H_{C}$ through the use of Eq. 5. The updated $H_{C}$ is again used in combination with $T_{C}$ to derive an update of $T_{A C}$, which in turn is used in conjunction with $T_{S}$ in Eq. 9, to produce 
a new estimate of $H_{S}$. Again, through the use of Eq. 6 a new estimate of $L E_{S}$ is obtained. This iteration process is continued until $L E_{S}>0$.

\section{Dual-angle component approach}

In the dual angle component approach, TSEB2D, the Priestley-Taylor iteration procedure is not used. Instead, the within-canopy temperature, $T_{A C}$, is estimated directly from the known component temperatures and the resistances, as follows:

$$
T_{A C}=\frac{\frac{T_{A}}{R_{A}}+\frac{T_{S}}{R_{S}}+\frac{T_{C}}{R_{X}}}{\frac{1}{R_{A}}+\frac{1}{R_{S}}+\frac{1}{R_{X}}} .
$$

The component sensible heat fluxes, $H_{C}$ and $H_{S}$, are then calculated directly from Eqs. 8 and 9. Note that the formulation of Eq. 14 is equal to the general expression of the aerodynamic temperature in two-source models (Merlin and Chehbouni 2004, Shuttleworth and Gurney 1990).

The component latent heat fluxes, $L E_{C}$ and $L E_{S}$, are simply calculated as rest-term from Eqs. 5 and 6. If $L E_{C}$ or $L E_{S}$ is below 0, then it is set to 0, and $H_{C}$ or $H_{S}$ is calculated as a rest-term from Eqs. 5 or 6, respectively. Basically, the TSEB2D approach is the same as the 2ANGLE model described by Kustas and Norman (1997).

\subsection{Material}

In order to ensure the proper extraction of the bulk soil and canopy component temperatures from dual-angle observations, some minimum difference in viewing angle of these observations is needed. The optimum viewingangle difference, usually between nadir and a particular zenith viewing angle, depends among other things on pixel resolution, local vegetation cover, and geometry, as well as on component temperature differences. For practical application, differences of some $40^{\circ}$ to $60^{\circ}$ are generally desirable (Colaizzi et al. 2012a, Kustas and Norman 1997, Merlin and Chehbouni 2004, Vining and Blad 1992).

Airborne data that fulfill these requirements were obtained during the EODIX campaign over a vineyard, centered at $39^{\circ} 03^{\prime} 35^{\prime \prime} \mathrm{N}$ and $02^{\circ} 06^{\prime} 04^{\prime \prime} \mathrm{W}$, in an agricultural test-site near Barrax, Spain. The area is extremely flat and located at an elevation of $700 \mathrm{~m}$ a.s.l. The campaign, carried out in June 2011, was specifically designed to obtain imagery with large differences in viewing angle. Unfortunately, during this campaign no detailed flux and component temperature observations were collected, which made it difficult to validate the model results. Over the vineyard, the only data available for 
validation was the water flux measured by a weighing lysimeter. Therefore, also data were used from the REFLEX campaign, which was flown in July 2012 covering the same vineyard and which was designed specifically to advance our understanding of land-atmosphere interaction processes over heterogeneous terrain.

The approach was first to demonstrate proper model performance over the Barrax site, using data from the REFLEX 2012 campaign. Although this "validation", was performed over a much larger area, covering also other land cover units than the vineyard, the main idea was to ensure that the model was providing reliable output for this area. Details of this study are described in Corbari et al. (2015) and a summary of the results is provided in Section 3.1. The actual comparison between the different model versions is then done using data from the EODIX campaign only. These data offered the possibility to extract bulk canopy and soil component temperatures for the vineyard, which is located at the center of the site. The procedure is outlined in Section 2.1.2 and the results are shown in Section 3.3. At the time of the campaigns, the vineyard in general is characterized by dry soils and dripirrigated grape stands. The drip irrigation system is not located directly on the soil, but some $\mathrm{cm}$ above it, watering the surface along the tube. As a consequence, to some degree grass is growing under the vine stands and at several locations, also in the corridors. The vineyard can best be described as relatively sparse; grape stands ranging in height from 1.0 to $2.5 \mathrm{~m}$ are planted in rows at about 3-meter intervals, but having a relatively dense canopy. This makes the site particularly suitable to test the TSEB series model parameterization, which was specifically designed for this type of landcover (Norman et al. 1995). The comparison is done by comparing model output from the single-angle and dual-angle TSEB versions using the data of the EODIX campaign. Since for all TSEB versions the net radiation and soil heat flux parameterizations are identical, the focus in the comparison study is on the turbulent flux output only.

A brief description of the observations and processing done for the input to and validation of the TSEB model is provided below. For a more complete description of the campaign observations see Timmermans et al. (2014) and van der Tol et al. (2015) for the REFLEX campaign and Mattar et al. (2014) for the EODIX campaign.

\subsection{Observations and data processing}

\subsubsection{REFLEX 2012 campaign}

\section{Ground-truth data}

During the campaign, which took place from 16 to 28 July 2012, three eddy covariance (EC) towers and a large aperture scintillometer (LAS) were in- 


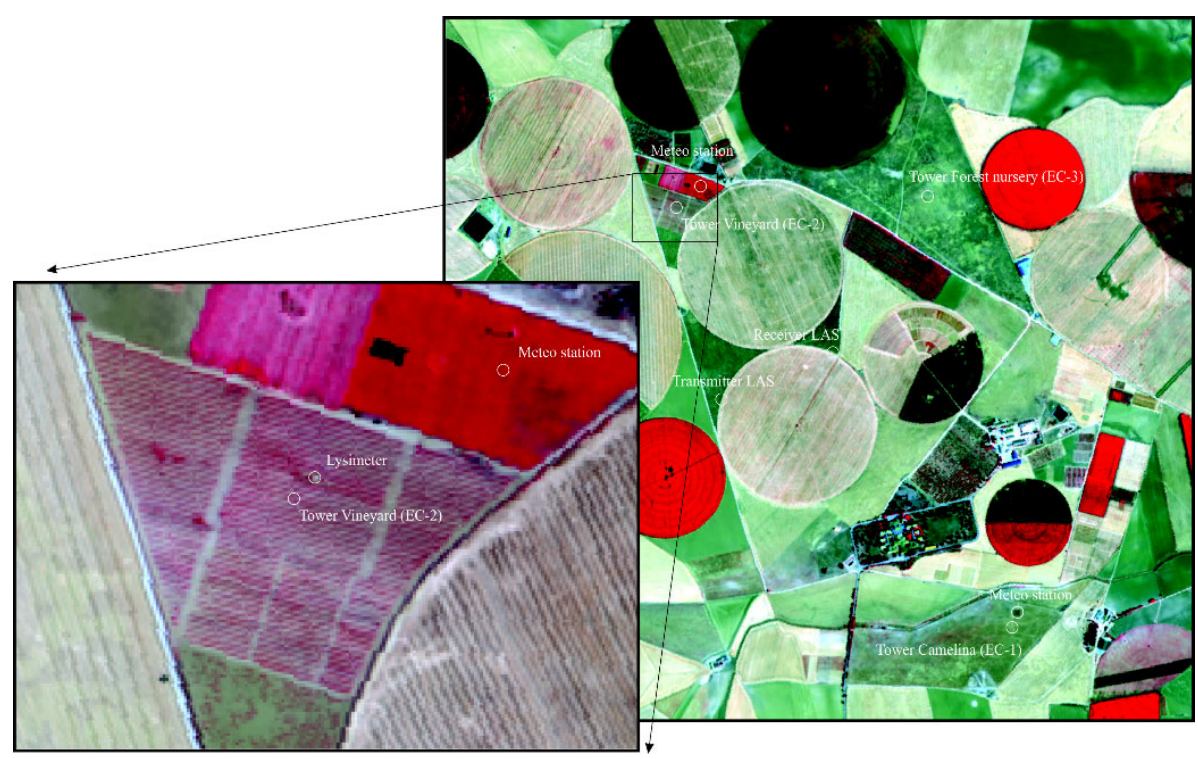

Fig. 1. Site overview with reference stations and flux tower sites. The zoom shows details of the vineyard site with a W-NW to E-SE crop row orientation, and lysimeter and flux tower positions.

stalled over different landcover units. The landcover units comprised a camelina field, a vineyard, a reforestation areak, and a large wheat-stubble field (see Fig. 1). Apart from the turbulent $H$ and $L E$ fluxes, at the flux towers also net radiation $(R n)$ and soil heat flux $(G)$ and standard meteorological parameters at three different heights were recorded. Required meteorological model inputs concern incoming shortwave radiation and air temperature, relative humidity, and wind speed at a certain reference level; see Corbari et al. (2015) for details. Since some crop and tree heights in the area were greater than the measurement level at the reference stations, the required meteorological model input was obtained by the average of the three EC stations at a reference height of $5 \mathrm{~m}$. Although a certain spatial variability in these variables is known to influence flux estimations over such heterogeneous sites (Timmermans W.J. et al. 2008) the spatial average (the standard deviation of air temperature was $0.9^{\circ}$, and $0.09 \mathrm{~ms}^{-1}$ for wind speed) was considered to be representative of the area with respect to the current model validation.

A detailed analysis of the turbulent flux observations is provided in van der Tol et al. (2015), which includes a discussion of the well-known closure problem. 


\section{Remote sensing data}

Required remote sensing based model inputs covered broadband surface albedo, normalized difference vegetation index, and surface temperature. These were obtained from optical airborne data acquired with the Airborne Hyperspectral Scanner (AHS), a sensor mounted on the Spanish Instituto Nacional de Tecnica Aerospacial (INTA) aircraft platform. An overpass at 09:28 UTC (11:28 local time) on 25 July 2012 was used for the current contribution. At-surface georeferenced reflectances (level 2b), resampled to a 4-meter pixel size, were provided by the INTA Remote Sensing Laboratory that was in charge of post-processing the airborne acquisitions. The atsurface reflectance was validated against field spectroscopy acquired in situ over a variety of landcover units, and showed good overall agreement. Details of these observations and post-processing steps are provided in de Miguel et al. (2015). Broadband surface albedo and NDVI were then derived from the surface reflectance in specific Red and Near Infrared (NIR) bands of the AHS sensor, following the same procedure as described in Timmermans et al. (2011). At-sensor radiances (level 1b) from the thermal AHS channels were processed by the Global Change Unit at the Faculty of Earth Physics at the University of Valencia, Spain, and validated against ground observations performed over several different landcovers. Land surface temperature and emissivity were retrieved simultaneously using the Temperature-Emissivity-Separation algorithm of Gillespie et al. (1998), adapted for use with the AHS data as described in Sobrino et al. (2009).

\subsubsection{EODIX 2011 campaign}

\section{Ground-truth data}

The necessary meteorological model input data were obtained from the lysimeter station located inside the vineyard, see zoom in Fig. 1. The meteorological observations were acquired at a height of $4 \mathrm{~m}$. They consisted of 15 -minute averages of incoming shortwave radiation, $\mathrm{S}^{\downarrow}$, and 1-hour averages of air temperature, $T_{A}$, relative humidity, R.H., and wind speed, $u$. The hourly averages were then interpolated to acquire estimates at the airborne overpass time (Table 1).

Table 1

Meteorological model input from the EODIX campaign

\begin{tabular}{|c|c|c|c|c|}
\hline Parameter & $\begin{array}{c}\mathrm{S}^{\downarrow} \\
{\left[\mathrm{Wm}^{-2}\right]}\end{array}$ & $\begin{array}{c}T_{A} \\
{\left[{ }^{\circ} \mathrm{C}\right]}\end{array}$ & $\begin{array}{c}\text { R.H. } \\
{[\%]}\end{array}$ & $\begin{array}{c}U \\
{\left[\mathrm{~ms}^{-1}\right]}\end{array}$ \\
\hline Value & 772 & 23.4 & 53.0 & 1.2 \\
\hline
\end{tabular}


Although no rainfall was recorded in the two weeks preceding the experiment, the last irrigation registered on the lysimiter was $20 \mathrm{~mm}$ on 7 June, five days before the airborne overpass. However, the irrigation scheme at this experimental test farm is rather irregular, both temporally as well as spatially. As a consequence, considerable variation exists in the degree of canopy stress within the vineyard. Locally stable conditions may occur, given the nature of the vineyard where sometimes hot bare corridors alternate with irrigated vines. On the other hand, also relatively stressed vines exist within the vineyard, due to the irregular irrigation, but also due to a variation in fractional vegetation cover (around $40 \%$ on average for the vineyard, but with minimum and maximum values ranging from 15 to $85 \%$, respectively). In the southern part of the vineyard, for example, less mature vine stands occur, characterized by a lower fractional cover of vine stands, but a more frequent irrigation. Typically at these places, but also at other locations within the vineyard, the corridors show the presence of grass, growing on water from the irrigation tubes.

The lysimeter station records hourly actual evaporation rates, which are interpolated for the overpass time of the airplane. The observation $\left(124 \mathrm{Wm}^{-2}\right)$ was used as an indication of the model performance, testing to which degree the estimations of LE fluxes were realistic and physically meaningful. A note has to be made with respect to dew which is recorded by the lysimiter almost all mornings in the period of the campaign, typically a few hours before the flight. Vaporization of this dew, mainly from the substrate, may also contribute to the LE flux during the flight overpass.

\section{Remote-sensing data}

Airborne optical imagery used to analyze the performance of the different model versions was also obtained from the Airborne Hyperspectral Scanner (AHS) operated by INTA. Two parallel flight lines acquired at 09:00 and 09:20 UTC on 12 June 2011 were utilized for this purpose. Local time is following CET, which is two hours later, but since the geographic position of the area is West, the true solar time is closer to 1 hour later than UTC. The flight lines were chosen such that they were parallel to each other and also parallel to the row orientation of the vineyard, in order to minimize potential local differences in shadowing effects due to differences in viewing azimuth. The campaign was specifically designed to obtain large differences in viewing angles. In order to achieve view zenith angles close to $60^{\circ}$, a wedge was placed under the sensor, to tilt it during the flight (Mattar et al. 2014). This produced a nadir viewing angle over the vineyard for the flight line acquired at 09:00 and a zenith viewing angle of $57^{\circ}$ over the vineyard for the flight line obtained at 09:20. 
Required general model inputs, broadband surface albedo, NDVI and surface temperature were obtained from the nadir flight in exactly the same manner as for the REFLEX 2012 campaign and are therefore not described here again. However, an ASD spectrometer was used for in situ measurements of surface reflectance and a CIMEL CE312-2 and IR120 radiometer for thermal emission over a large number of selected sites encompassing different landcover units. An RMSE of 0.03 [-] was found for reflectance and an RSME of $1.5[\mathrm{~K}]$ for land surface temperature, equal to the values found in previous campaigns over the same area using the same sensor (Mattar et al. 2014, Sobrino et al. 2006, 2009).

In addition, the required bulk soil and canopy component temperature observations were obtained, using Eqs. 12 and 13, from the two parallel flight lines, which were characterized by viewing zenith angle differences over the vineyard of around $57^{\circ}$. In order to take the small time difference of 20 minutes between the two successive flight lines into account, a correction of $T_{R}$ was made, using the ratio of $T_{R}\left(\varphi_{1}\right) / T_{R}\left(\varphi_{2}\right)$ taken from a homogeneously vegetated area (dense grass cover) just north of the vineyard. However, the differences obtained were almost negligible.

\section{RESULTS AND DISCUSSION}

\subsection{Validation of single-angle model over Barrax (REFLEX 2012 campaign)}

TSEB model output for $R n, G, H$, and $L E$ as derived from the AHS overpass at 09:28 UTC (11:28 local time) on 25 July 2012, was validated against ground observations over four different landcover units. For this purpose, the so-called field-of-view of the local sensors needs to be determined. This is especially important when dealing with high-resolution imagery as is the case in the underlying study. For the net radiation sensor, $99 \%$ of the observations originate from a circle whose diameter is 10 times the sensor height (i.e., $5 \mathrm{~m}$ ), although ground surfaces closer to the sensor have a higher weighting. A window of $10 \times 10$ pixels (i.e., $40 \times 40 \mathrm{~m}$ ) was selected around the location of the observation. The same was done for the soil heat flux observations, which are characterized by a high spatial variation. To at least take this effect into account, we chose a similar window as for the net radiation observations. For the turbulent fluxes, a different strategy is followed. The "field-of-view", or footprint (Vesala et al. 2008), of these sensors depend on terrain characteristics, wind speed, and wind direction. The procedure outlined in Timmermans et al. (2009) is used to calculate the footprints of the observation towers at the moment of airborne overpass. Footprintweighted averages of the model output for $H$ and $L E$ were then compared to the ground observations. 
Model performance was evaluated using difference statistics comprising of the mean absolute difference (MAD), the mean absolute error (MAE), and the root mean square difference (RMSD), see Table 2.

Table 2

Difference statistics for the four observation sites

\begin{tabular}{|l|c|c|c|c|}
\hline \multicolumn{1}{|c|}{ Statistics } & $H$ & $L E$ & $G$ & $R n$ \\
\hline MAD $\left[\mathrm{Wm}^{-2}\right]$ & 22.5 & 8.7 & 85.0 & 51.5 \\
MAE [\%] & 13.9 & 29.4 & 51.2 & 13.6 \\
RMSD [Wm $\left.{ }^{-2}\right]$ & 28.0 & 10.0 & 87.2 & 58.3 \\
\hline
\end{tabular}

Although only limited ground observations were available for this particular study, a reasonably good agreement between observed and modelled fluxes is noted, especially for the turbulent fluxes. An analysis of the model performance per landcover and per flux component is beyond the scope of the current contribution, but a detailed discussion and tower footprints can be found in Corbari et al. (2015). For our study, we regard the overall model performance of TSEB1 with respect to the estimation of both radiative and especially turbulent fluxes over this site as reliable.

\subsection{Soil and canopy component temperatures}

The nadir $T_{R}$ and $f_{C}$ maps as well as the component temperature maps are shown in Fig. 2.

As can be noticed, and also seen in the zoom of Fig. 1, two main corridors exist in the vineyard, which are characterized by a very low fractional cover. As they are oriented perpendicularly to the flight lines, the difference in fractional cover between the two flight lines was minimal. Since this difference is in the denominator of Eq. 12, the determination of $T_{S}$ can become very sensitive to errors. These pixels, as well as other pixels where the difference in fractional cover was minimal, were therefore excluded from the analysis.

In a spatial context, clearly the parts in the vineyard that are characterized by a higher $f_{C}$ show a lower $T_{R}$, and vice versa, as may be expected. Another clear phenomenon throughout the vineyard is the lower $T_{S}$ at high $f_{C}$, and vice versa. This is primarily caused by the higher radiation extinction within the canopy (shadow), resulting in a lesser warming up of the soil/substrate during the morning hours. Therefore, if homogenous soil conditions are assumed and $T_{R}$ is constant, a higher $f_{C}$ will result in a lower $T_{S}$ and, according to Eq. 1, thus in a higher $T_{C}$. Despite the fact that soil conditions and $T_{R}$ are not homogeneous throughout the vineyard, this (i.e., a lower 


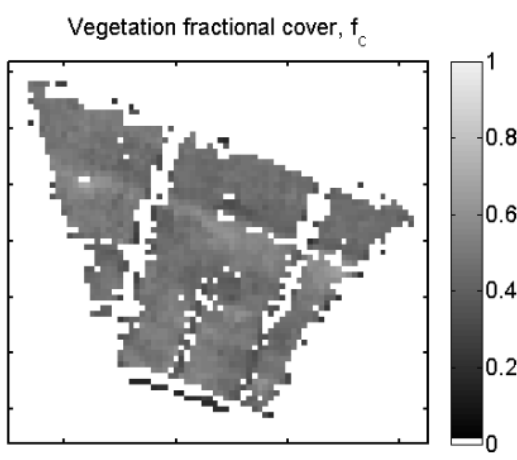

Radiometric surface temperature, $\mathrm{T}_{\mathrm{R}}\left[{ }^{\circ} \mathrm{K}\right]$
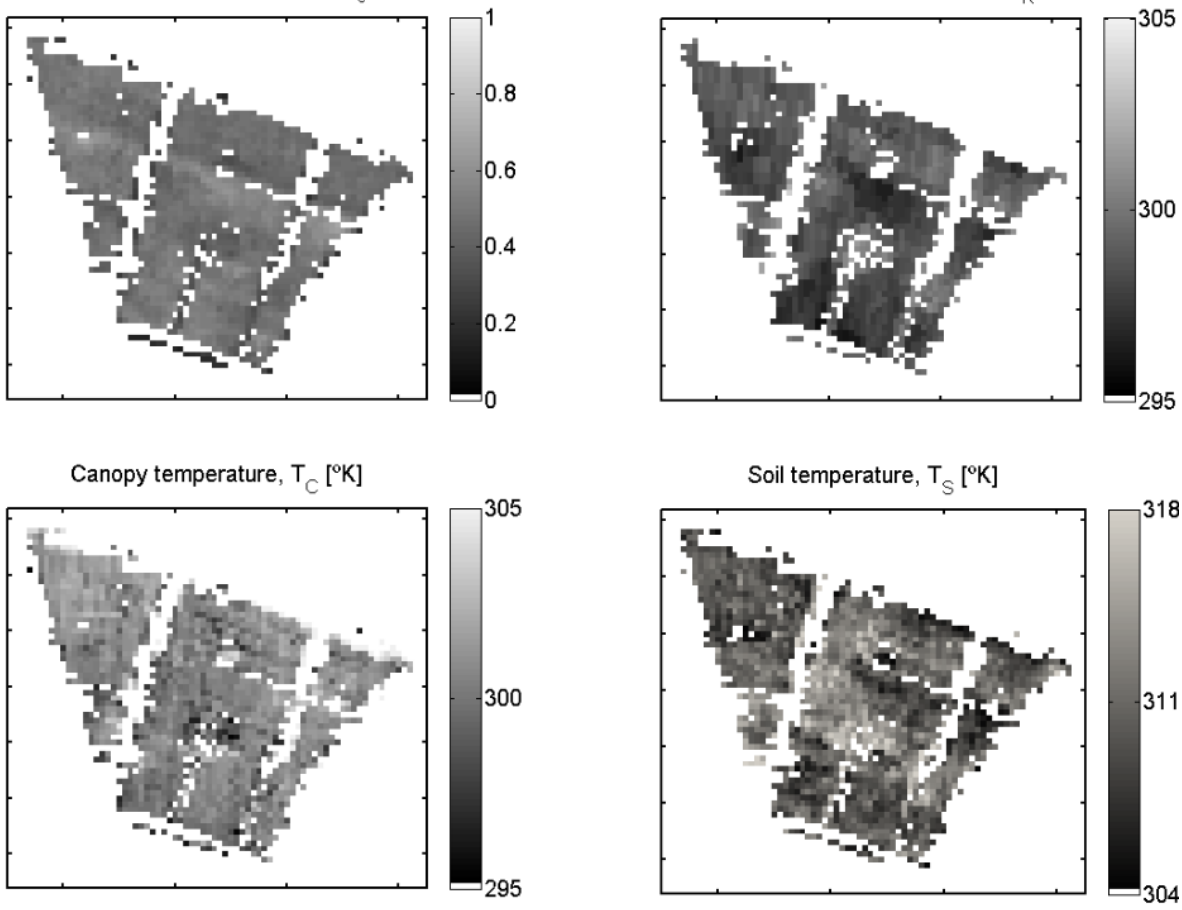

Fig. 2. Retrieved $f_{C}, T_{R}, T_{C}$, and $T_{S}$ maps over the Barrax site for 12 June 2011 (EODIX campaign).

$T_{S}$ is accompanied by a higher $T_{C}$ and vice versa) is what is seen here to a certain extent. At a first instance, this does not seem physically very realistic, since relatively high $T_{C}$ and relatively low $T_{S}$ would indicate stressed vegetation over a relatively cold soil and vice versa. However, given the variation in characteristics of the vineyard, where locally in the corridors shallow rooted grass is fed by water from the irrigation tubes, situations with stressed vines and low temperatures for the soil/substrate do occur. The opposite situation, i.e., unstressed vegetation occurring over a relatively hot soil/ substrate, is rather common in a drip-irrigated system. Which situation prevails and whether this is realistic in the current situation is discussed in Section 3.3 .

In an absolute sense, the bulk soil and canopy component temperatures obtained from the dual angle airborne observations over the vineyard showed average values of 310.6 and $300.7 \mathrm{~K}$, respectively, with standard deviations of 0.62 for the soil and 0.30 for the canopy. Although these "observed" temperatures are actually derived from Eqs. 12 and 13, and as such are not actual observations of $T_{S}$ and $T_{C}$, they will be referred to as "ob- 
served" from here onwards, to differentiate them from soil and canopy temperatures as modelled by TSEB1. The soil temperatures ranged from 303.8 to $318.1 \mathrm{~K}$, while observed canopy temperatures were between 298.0 and $302.6 \mathrm{~K}$. Unfortunately, during the EODIX 2011 campaign, no detailed ground observations of soil and leave component temperatures were available. However, given an observed air temperature of $296.5 \mathrm{~K}$ and a vapor pressure deficit of $1.2 \mathrm{kPa}$ the observations are in agreement with theoretical limits as defined by Jackson et al. (1981) and Gardner et al. (1992), or more recently by Colaizzi et al. (2012b). They report that typical values for foliage temperatures under these circumstances may range from $1.5 \mathrm{~K}$ below air temperature for potentially transpiring crops to $5.0 \mathrm{~K}$ above air temperature for non-transpiring crops, although it is stated that measurements may occasionally exceed these limits.

Similar observations were made by Timmermans J. et al. (2008) during the Sen2Flex campaign over the Barrax vineyard. Apart from measuring sunlit and shaded soil temperature, they used contact probes to measure individual leaf temperatures of sunlit and shadowed, old and young leaves, at different heights in the canopy. They found within-canopy differences in leaf temperature, ranging from $5 \mathrm{~K}$ below air temperature to $6 \mathrm{~K}$ above air temperature in late morning, and reported standard deviations as large as $3.1 \mathrm{~K}$ for soil and $1.3 \mathrm{~K}$ for the canopy component temperatures, within a $5 \mathrm{~m}$ radius. The canopy temperatures observed in the current study are obviously biased towards the upper theoretical limit with respect to air temperature. This may indicate that, though irrigated, the crops are transpiring at a subpotential rate.

A comparison of the component temperatures with modelled values of soil and canopy temperatures obtained from TSEB1 is provided in Fig. 3.
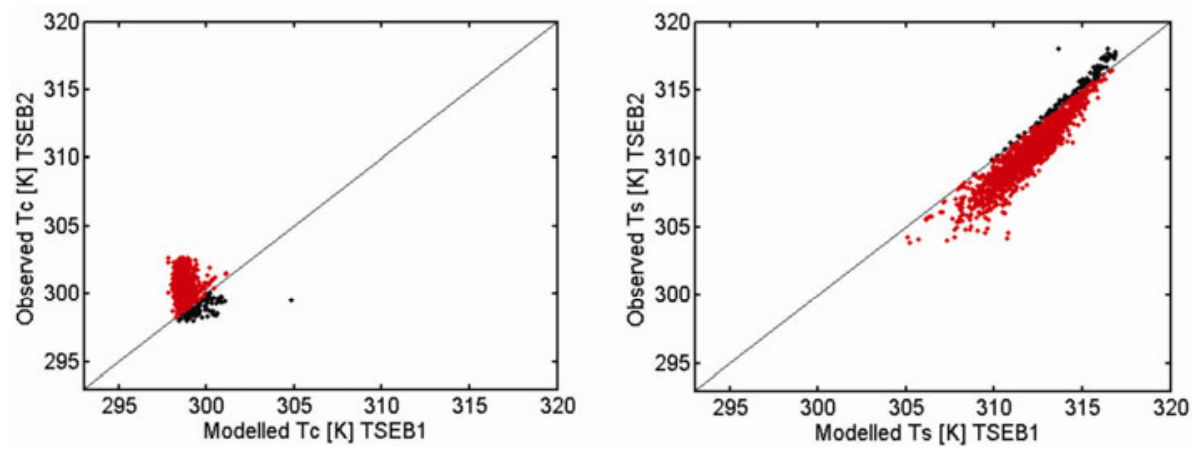

Fig. 3. Observed versus estimated component temperatures for 12 June 2011. In red/orange pixels are shown where $T_{S}$ observed $<T_{S}$ modelled and/or $T_{C}$ observed $>T_{C}$ modelled. 
For a large part of the vineyard, the modelled values of $T_{C}$ are lower than observations ( $298.7 \mathrm{~K}$ versus $300.7 \mathrm{~K}$ on average, respectively) and in much of the vineyard the values of modelled $T_{S}$ are higher than observed $(312.1 \mathrm{~K}$ versus $310.6 \mathrm{~K}$ on average, respectively). Because of the importance of this phenomenon for this study, the pixels where this occurs are displayed in red (or orange) in Fig. 3 and in following sections. Apart from the average differences, the standard deviation in the modelled values of both $T_{C}$ and $T_{S}$ is smaller than for the observations. Observed $T_{C}$ shows a standard deviation of $0.30 \mathrm{~K}$ versus a standard deviation of $0.20 \mathrm{~K}$ for the modelled values. For $T_{S}$ the standard deviations for observations and modelled values are $0.62 \mathrm{~K}$ and $0.49 \mathrm{~K}$, respectively.

\subsection{Inter-comparison between single-angle and dual-angle models (EODIX 2011 campaign)}

\subsubsection{Single-angle (TSEB1) and dual-angle iteration approach (TSEB2I)}

Model output from TSEB1 is plotted versus TSEB2I output for the turbulent fluxes in Fig. 4. Although a reasonable agreement and clear correlation, $R$,
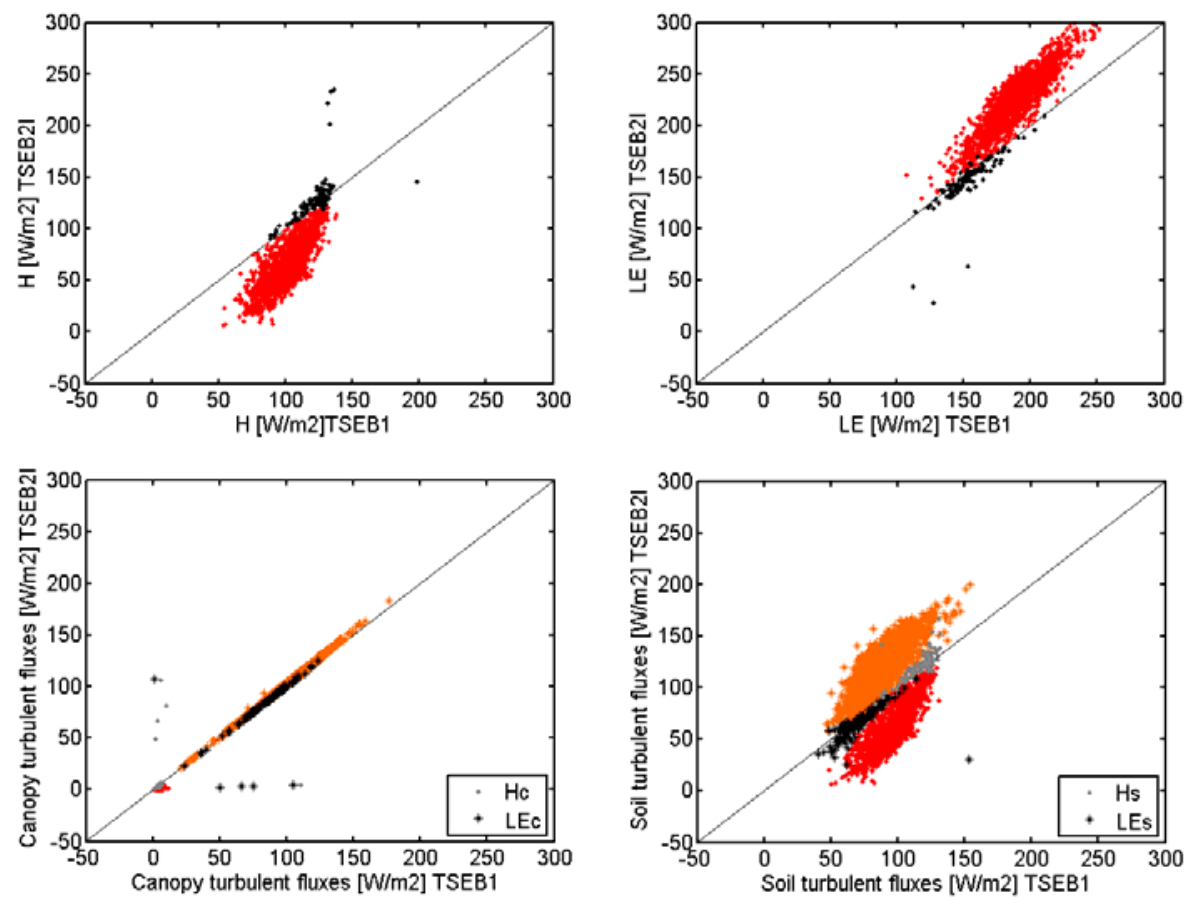

Fig. 4. Turbulent fluxes and their components (lower panels) from TSEB1 versus TSEB2I. In red/orange pixels are shown where $T_{S}$ observed $<T_{S}$ modelled and/or $T_{C}$ observed $>T_{C}$ modelled. 
between the two model versions ( $R$ is equal to 0.91 for $L E$ and 0.82 for $H$ ) is noted in this figure, there are also clear differences.

A mean difference of $-31.9 \mathrm{Wm}^{-2}$ and RMSD of $32.9 \mathrm{Wm}^{-2}$ of sensible heat flux by TSEB2I with respect to TSEB1 output is noted and a similar (available energy, $R n-G$, is the same for both models) over-estimation, and RMSD of latent heat flux by TSEB2I with respect to TSEB1 can be seen. An explanation for this is found by a closer examination of the component flux outputs of both model versions, which are shown in Fig. 4. Model output statistics, including those from the TSEB2D model version, are presented in Table 3 in the next section.

Table 3

Model output statistics for TSEB1 and TSEB2I: mean $(\bar{x})$ and standard deviation $(\sigma)$.

\begin{tabular}{|l|c|c|c|c|c|c|c|c|c|c|c|c|}
\hline \multirow{2}{*}{ Model } & \multicolumn{2}{|c|}{$H$} & \multicolumn{2}{c|}{$H_{C}$} & \multicolumn{2}{c|}{$H_{S}$} & \multicolumn{2}{c|}{$L E$} & \multicolumn{2}{c|}{$L E_{C}$} & \multicolumn{2}{c|}{$L E_{S}$} \\
\cline { 2 - 13 } & $\bar{x}$ & $\sigma$ & $\bar{x}$ & $\sigma$ & $\bar{x}$ & $\sigma$ & $\bar{x}$ & $\sigma$ & $\bar{x}$ & $\sigma$ & $\bar{x}$ & $\sigma$ \\
\hline TSEB1 & 102 & 4.0 & 5 & 2.7 & 97 & 3.7 & 185 & 6.8 & 97 & 6.8 & 88 & 4.2 \\
TSEB2I & 68 & 7.7 & 3 & 4.2 & 66 & 7.0 & 219 & 10.8 & 100 & 7.5 & 119 & 7.0 \\
TSEB2D & 142 & 5.2 & 69 & 10.0 & 73 & 6.6 & 145 & 5.7 & 34 & 8.8 & 112 & 6.7 \\
\hline
\end{tabular}

In the left panel of Fig. 4 the canopy component fluxes of TSEB1 are plotted against those of TSEB2I, and in the right panel the soil components are shown.

The canopy component fluxes of TSEB1 and TSEB2I are identical for almost all pixels in the vineyard. This is due to the Priestley-Taylor iteration procedure that was used here in both versions of the model. If the first estimates of $T_{S}$, in TSEB1, or observations of $T_{S}$, in TSEB2I, yield an $H_{S}$ that is smaller than $R n_{S}-G$, then the first estimate of $L E_{S}>0$. This is the situation for nearly all points, which means that the two versions yield the same values for $L E_{C}$ and $H_{C}$ fluxes under these circumstances.

Since for almost all pixels the canopy component fluxes are identical for the two versions of the model and $L E_{S}$ is determined as a rest-term, the differences for $H$ and $L E$ are entirely regulated by the differences for $H_{S}$. The TSEB2I model output for $H_{S}$ is almost everywhere smaller than in the TSEB1 version, see Fig. 4 right panel. Examination of Eq. 9 reveals that differences in $H_{S}$ may be invoked by differences in $T_{A C}$, in $R_{S}$ or in different values for $T_{S}$.

Many of the observed values of $T_{C}$ are larger than the TSEB1 model output for $T_{C}$, see Fig. 3. Equation 1 shows that for $T_{S}$ the opposite then must hold true, which is confirmed in the right panel of Fig. 3. Lower values of $T_{S}$ in TSEB2I potentially yield lower values for $H_{S}$. 
Model differences for $R_{S}$ are mainly regulated by differences in the coefficient $a$ in $T_{C}$, following Eq. 5 in Kustas and Norman (1999). Larger $T_{C}$ values in TSEB2I, and thus lower $T_{S}$ values, result in lower values for $a^{\prime}$ and thus in higher $R_{S}$ values, since wind speed values do not differ significantly between model versions. Higher $R_{S}$ values potentially yield lower values for $H_{S}$ in TSEB2I as well.

Within canopy, air temperature, $T_{A C}$, is obtained from Eq. 8. Since values for $R_{X}$, mainly driven by wind speed, and $H_{C}$ are similar in both versions of the model, higher values of $T_{C}$ in TSEB2I also yield higher values of $T_{A C}$ in TSEB2I. Larger values of $T_{A C}$ potentially yield lower values of $H_{S}$ in TSEB2I as compared to TSEB1.

The model differences for $R_{S}$ and $T_{A C}$ described above are illustrated in Fig. 5. In the current contribution we have used the modified formulation for $R_{S}$, as given in Eq. 5 in Kustas and Norman (1999). Using the original $R_{S}$ formulation (Norman et al. 1995), which is independent of the difference between $T_{S}$ and $T_{C}$, reduced differences for $R_{S}$, but did not significantly influence model differences for $H_{S}$ output. Since $H_{C}$ is negligible for almost entire vineyard in both TSEB1 and TSEB2I parameterizations, $T_{A C}$ and $T_{C}$ are almost identical, see Eq. 8. Therefore, the shape of the right panel of Fig. 5 is rather similar to the left panel of Fig. 3.

Resuming, larger values of observed $T_{C}$ as compared to modelled $T_{C}$ in TSEB1 for all three parameters that have a direct influence on $H_{S}$ yield lower values of $H_{S}$. This is confirmed by the red pixels in the lower right panel (and thus upper left panel) of Fig. 4, which are all below the 1:1 line. On the other hand, if lower values of $T_{C}$ were observed than for TSEB1-modelled $T_{C}$, this would yield higher values of $H_{S}$ in TSEB2I than in TSEB1. Since many of the observed values of $T_{C}$ were higher than those of the modelled $T_{C}$, the dual angle model output for $H_{S}$, and thus for $H$, is lower.
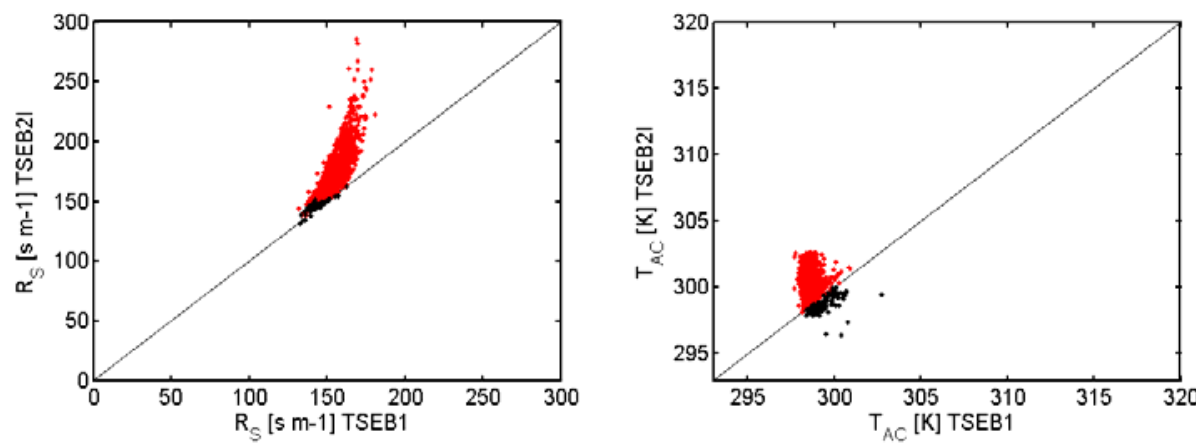

Fig. 5. Left panel $R_{S}$, right panel $T_{A C}$. 


\subsubsection{Single-angle (TSEB1) and dual-angle component approach (TSEB2D)}

The model output from TSEB1 is plotted versus TSEB2D output for the turbulent fluxes in Fig. 6. Agreement and correlation between the two models is less than between TSEB1 and TSEB2I. Correlation, $R$, between the two model versions is equal to 0.55 for $L E$ and 0.30 for $H$, whereas the mean differences and RMSD between TSEB2D and TSEB1 are $+39.4 \mathrm{Wm}^{-2}$ and $40.2 \mathrm{Wm}^{-2}$, respectively, for $H$. Again the difference statistics for $L E$ are equal and opposite to those of $H$. Interestingly, the mean difference has the opposite sign as compared to TSEB2I. Once again, an explanation is found by a closer examination of the component flux outputs of both model versions, as shown in Fig. 6. Model output statistics are presented in Table 3.

For the soil component fluxes, shown in the right panel of Fig. 6, a similar reasoning may be followed as described in the last paragraph of Section 3.3.1. Therefore, the right panel of Fig. 6 is very similar to the right panel of Fig. 4.
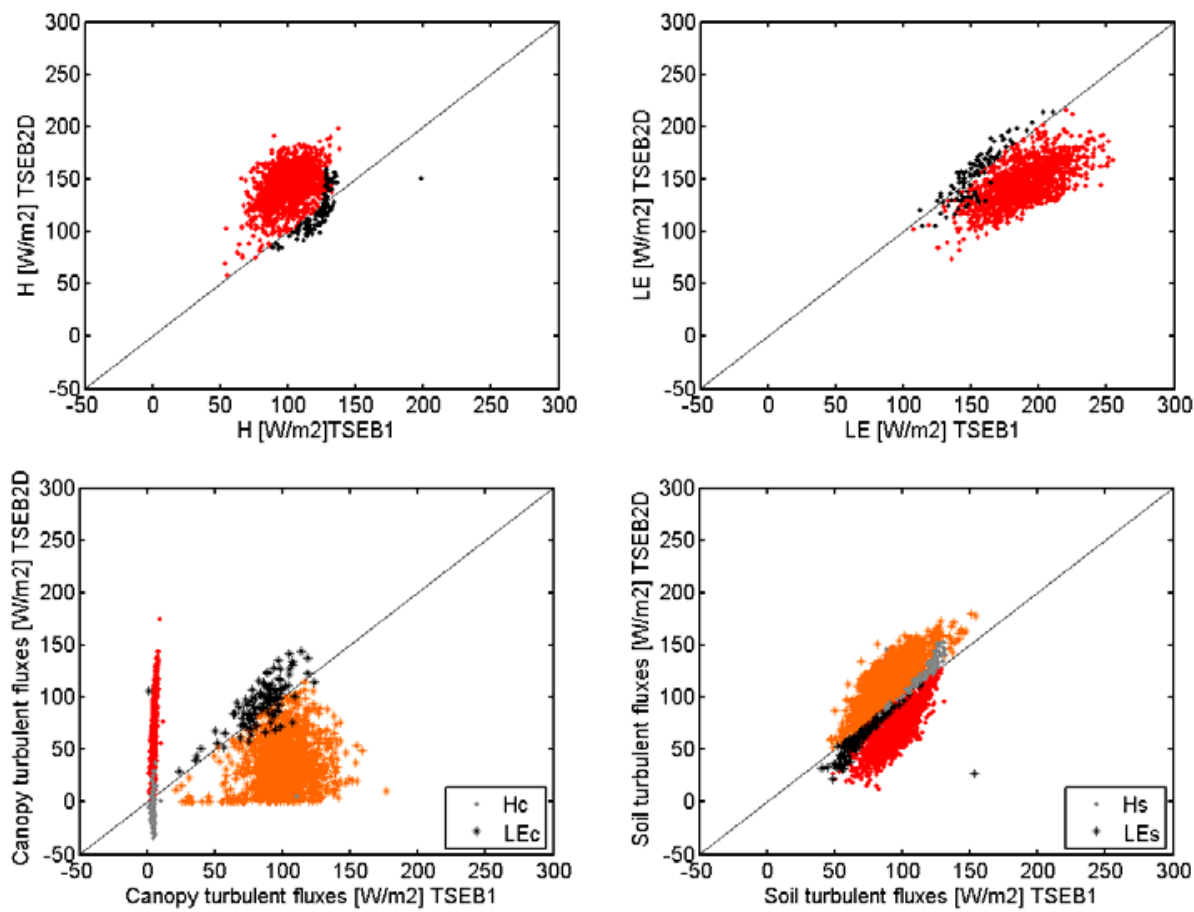

Fig. 6. Turbulent fluxes and their components (lower panels) from TSEB1 versus TSEB2D. In red/orange pixels are shown where $T_{S}$ observed $<T_{S}$ modelled and/or $T_{C}$ observed $>T_{C}$ modelled. 
However, a striking difference between the two model versions can be observed with respect to the canopy component fluxes. In the TSEB2D approach, values for $H_{C}$ range from -35 to $175 \mathrm{~W} \cdot \mathrm{m}^{-2}$. However, in the TSEB1 approach, for almost the entire vineyard, the canopy is transpiring at the potential rate, resulting in negligible values for $H_{C}$ under the current circumstances.

In the absence of stressed vegetation, the first estimate of the partitioning of $R n_{C}$ into $L E_{C}$ and $H_{C}$ in TSEB1 is determined entirely by the slope of the saturation vapor pressure, $\Delta$, which depends solely on air temperature. In the temperature range between 25 and $35^{\circ} \mathrm{C}$, which are typical summertime values at this latitude, the first estimate of the portion of $R n_{C}$ that is consumed by latent heat exchange ranges from 95 to $105 \%$. This leaves only negligible amounts of energy available for sensible heat exchange between the canopy and the air. Under TSEB1, these first estimates will not change as long as the first estimate of the soil component of the sensible heat flux, $H_{S-1}$, is smaller than the available amount of energy for the soil, i.e., $R n_{S}-G$. In other words, these first estimates will not change as long as $L E_{S-1}$ is larger than 0 . This is the case for almost all pixels in the vineyard.

Following Eq. 8, negligible sensible flux over the canopy results in a within-canopy air temperature very similar to the canopy temperature. One could reason that in such a case the sensible heat flux over the soil is driven by the difference between $T_{S}$ and $T_{C}$. Given that the first estimate of $T_{C}$ in TSEB1 is the average between air temperature and radiometric surface temperature, this means that the first estimate of $H_{S}$ is driven by the difference between air and radiometric surface temperature as a function of fractional canopy cover, $f_{C}$, over the surface resistance. Using this information in the first estimate of $L E_{S}$ provides a simple first check whether given conditions will predict water-stressed canopy conditions. Under the current conditions, this first estimate of $L E_{S}$ is positive everywhere, meaning no lowering of $\alpha_{\mathrm{PT}}$ in Eq. 11 occurred at any location. Hence the canopy sensible heat flux estimates in TSEB1 (as for TSEB2I) are negligible (Table 3). This is remarkable, given that the observed canopy component temperatures are "biased towards the upper theoretical limit with respect to air temperature", indicating potentially relatively high canopy sensible heat fluxes. It should be noted at this point that for TSEB1 (and for TSEB2I) to predict stressed conditions $L E_{S}$ has to be zero. Therefore, situations where the upper soil is wet (due to dew, or just after a rain or irrigation event) and plants (which have their roots at a deeper and potentially drier soil layer) are stressed, cannot be modelled by TSEB1 nor TSEB2I. This is a drawback of the model for agricultural applications.

Contrary to TSEB1 and TSEB2I, in TSEB2D the canopy turbulent fluxes, $H_{C}$ and $L E_{C}$, are not estimated from $R n_{C}$, but from the canopy tempera- 
tures directly. As such, a potential error in $R n_{C}$ will affect TSEB1- $H_{C}$ and TSEB2I- $H_{C}$, but will not affect TSEB2D- $H_{C}$. The TSEB2D estimates for canopy sensible heat fluxes, that range from -35 to $175 \mathrm{~W} \cdot \mathrm{m}^{-2}$, are on average $69 \mathrm{~W} \cdot \mathrm{m}^{-2}$ and show a standard deviation equal to $10.0 \mathrm{~W} \cdot \mathrm{m}^{-2}$. This relatively large range is also observed by Kustas and Norman (1997) who state that in general an approach that uses the component temperatures directly produces considerable scatter. Of course, we do not have component flux observations at the scale of individual vines, but given the observed range in canopy temperatures a certain scatter in canopy sensible heat fluxes may be expected. This is in accordance with the nature of this vineyard, where both full-grown mature vine stands exist next to younger vine stands with a lower fractional vegetation cover and a higher irrigation supply. Although no individual canopy flux observations are available, the range in TSEB2D model output therefore seems realistic. The larger rate of latent heat from the soil could be related with the dew registered on the lysimeter as mentioned earlier.

In TSEB2D, the canopy sensible heat fluxes were estimated following Eq. 8, where $\rho_{a}, C_{p}$, and $T_{C}$ are the observed parameters, $R_{X}$ is estimated as given in Eq. A.8 in Norman et al. (1995) and $T_{A C}$ is estimated following Eq. 14. Since the main variation in $R_{X}$ originates from wind speed just above the canopy, no large differences between TSEB1 and TSEB2D are noted, see the upper left panel of Fig. 7. Given the large spread in $H_{C}$ for TSEB2D one might expect an effect on $T_{A C}$ as well. This effect, which is a reduction in standard deviation and relatively lower values, is shown in the upper right panel of Fig. 7. $T_{A C}$ is derived not only from air and component temperatures but also depends directly on the resistances (Eq. 14). How they relate to the soil and aerodynamic resistances in TSEB1 is plotted in the lower panels of Fig. 7. Larger values and larger standard deviation for $R_{S}$, similar to TSEB2I, are seen for TSEB2D as compared to TSEB1. To a lesser extent, the opposite is seen for $R_{A}$, lower standard deviation and partly lower values in TSEB2D. Apparently, the interplay between component temperatures and resistances Eq. 14 has a compensating, lowering effect on $T_{A C}$ here.

Since $T_{A C}$ depends not only on observed air and component temperatures but on all resistances as well, the different resistance parameterizations are of crucial importance for obtaining accurate component flux estimates here. Validation of these parameterizations for the current study would have involved further experimental observations of within- and above-canopy wind, temperature, and flux profiles. However, this is beyond the scope of the current study, whose objective was merely to investigate the effect of using observed component temperatures instead of model-derived component temperatures on model output. 

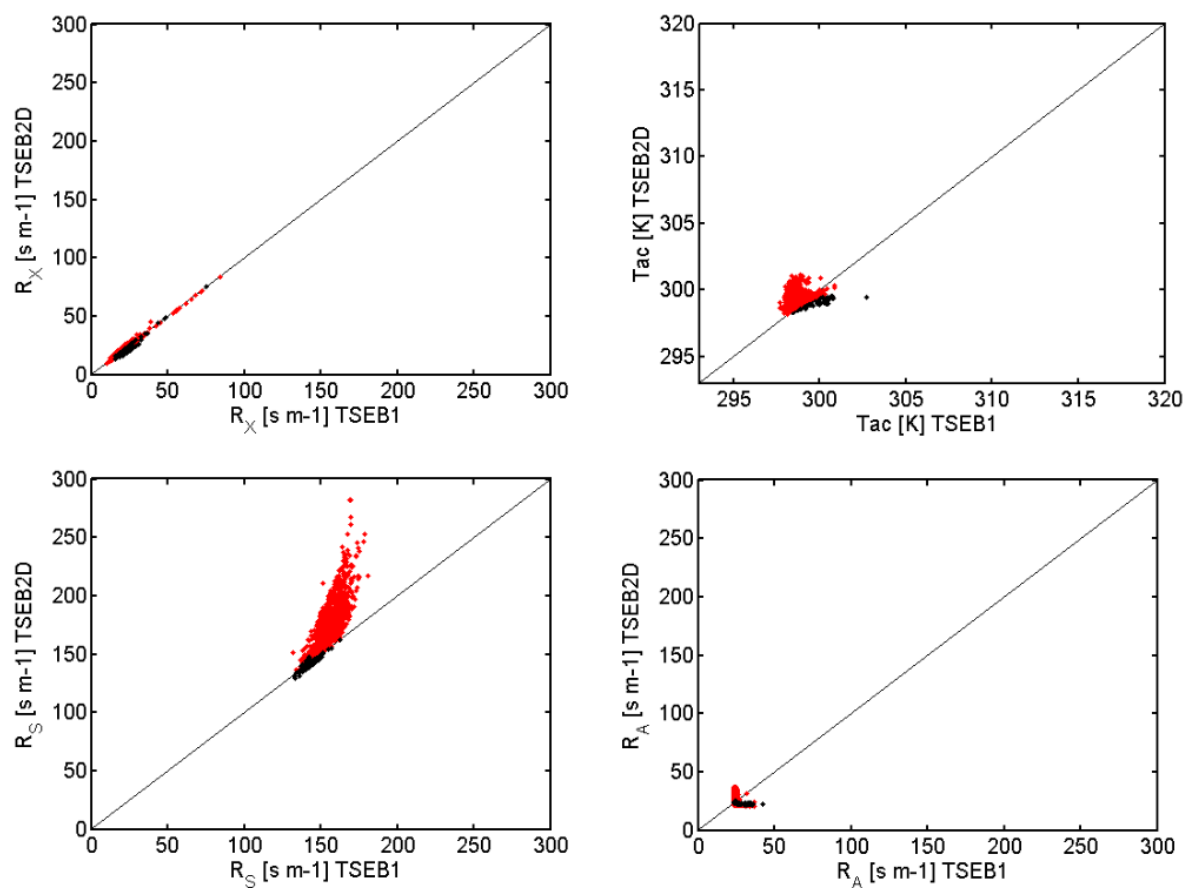

Fig. 7. Comparison between TSEB1 and TSEB2D for the within-canopy temperature, $T_{A C}$, and the resistances, $R_{X}, R_{S}$, and $R_{A}$.

\subsubsection{Concluding remarks}

Summarizing, using the observed component temperatures in TSEB2D results in higher values for $H$, and lower values for $L E$, as compared to TSEB1 under current conditions. The opposite holds true for TSEB2I; here, using the observed component temperatures results in lower values for $H$ and higher values for $L E$.

The latter is explained entirely by the soil components for TSEB1 and TSEB2I, as described extensively in Section 3.3.1. The soil components for TSEB2I and TSEB2D are estimated in a similar manner. Both use the observed $T_{S}$, resulting in a lower $H_{S}$ estimate for both models with respect to TSEB1. Since no PT-iteration took place, no "correction" was performed on $L E_{S}$ in TSEB2I, hence the lower right panels of Figs. 4 and 6 have a very similar shape. The (small) difference in magnitude of the soil fluxes of TSEB2I and TSEB2D is regulated mainly by the difference in magnitude of $T_{A C}$ because $R_{S}$ for the two models is almost identical since wind speed values do not differ significantly between model versions.

Because the estimations of $H$ fluxes from TSEB2D on average are higher than those of TSEB1, the under-estimation of $H_{S}$ by TSEB2D with respect to 
TSEB1 has to be more than compensated by the over-estimation of $H_{C}$. The average difference between modelled and observed canopy temperatures is $2.0^{\circ} \mathrm{K}$, whereas for the soil temperatures this is only $1.5 \mathrm{~K}$, meaning that potentially the effect of using observed component temperatures on $H_{S}$ is smaller than on $H_{C}$. This effect is even emphasized by the resistances, because $R_{S}$ becomes larger when using the observed component temperatures, whereas $R_{X}$ remains (almost) unchanged. Therefore, the estimates of $H$ from TSEB2D are higher than those of TSEB1 when $T_{C}$ observed is larger than $T_{C}$ modelled. This is reflected by the red pixels in the upper left panel of Fig. 6 , which are all above the 1:1 line.

Now, the question remains which of the model versions performs better. Unfortunately we do not have (component) flux measurements. However, an indication of the model performance may be obtained from Table 4, where TSEB1, TSEB2I, and TSEB2D model outputs for $L E$ are compared with the lysimeter measurements. The best fit corresponds to the TSEB2D output, although the agreement with TSEB1 is still within generally accepted ranges. The TSEB2I output shows the largest discrepancy, suggesting that using the Priestley-Taylor approach combined with observed component temperatures performs worse than using the Priestley-Taylor approach only.

Table 4

LE model results for TSEB1, TSEB2I, and TSEB2D

versus the lysimeter observation

\begin{tabular}{|c|c|c|c|c|}
\hline $\begin{array}{c}\text { Latent heat flux } \\
{\left[\mathrm{Wm}^{-2}\right]}\end{array}$ & Lysimeter & TSEB1 & TSEB2I & TSEB2D \\
\cline { 2 - 5 } & 124 & 163 & 201 & 125 \\
\hline
\end{tabular}

\section{SUMMARY}

Validation of the widely used single-angle model, TSEB1, over a very heterogeneous agricultural area in a semi-arid environment showed good results that are comparable to previous validations work done for the model. Turbulent flux exchanges showed a particularly good fit with respect to ground observations.

Dual-angle measurements yielded observations of soil and canopy component temperatures that showed a larger spread than modelled values for $T_{S}$ and $T_{C}$. No ground observations of component temperatures were made during the overpass but values showed very similar responses compared to observations made during previous and comparable campaigns and were within theoretical limits. Values obtained for canopy temperature indicated relatively stressed vegetation stands. This was not confirmed by results of the TSEB1 model, which generated values for $T_{C}$ that were generally lower than observations and $T_{S}$ that were generally higher than observations. 
The output of two types of the dual angle version of TSEB, comparable to those described in Kustas and Norman (1997) and Colaizzi et al. (2012a), was compared with the output of the single-angle model version. The first version, TSEB2I, contains a similar iteration procedure to that of the singleangle version, invoking a step-wise lowering of the Priestley-Taylor coefficient. The second version, TSEB2D, without iteration procedure, utilizes the observed component temperatures to estimate component sensible heat fluxes directly.

Reasonable agreement and correlations between TSEB1 and TSEB2I model outputs for the turbulent fluxes were found. TSEB1 generates slightly lower values for $L E$ and slightly higher values for $H$ than TSEB2I. This is entirely regulated by the soil component of the fluxes, since the canopy flux estimates of both model versions are similar due to the iteration procedure used in both model versions. This procedure yields a potentially transpiration canopy in over almost the entire vineyard under the current conditions. The higher values for $T_{S}$ obtained in TSEB1 as compared to observed values for $T_{S}$ always result in higher estimates of $H_{S}$ in the current parameterization. $L E_{S}$ is calculated as a rest-term, so TSEB1 estimates are lower than estimates of TSEB2I. TSEB1 results for $H$ are therefore higher than for TSEB2I and TSEB1 results for $L E$ are lower than for TSEB2I.

There is considerably less agreement between the TSEB1 and TSEB2D model outputs. Since the soil components are estimated in a similar manner as for TSEB2I, the reason for the poorer agreement lies in the estimation of the canopy component fluxes. Under the current conditions, TSEB1 predicts potential transpiration rates for the entire vineyard, which yields negligible $H_{C}$ estimates overall. However, using observed $T_{C}$ in TSEB2D to directly estimate $H_{C}$ yields values that range from -35 to $175 \mathrm{~W} \cdot \mathrm{m}^{-2}$. Even though no ground observations are available for these component fluxes, these values seem to be more realistic under the given conditions. Moreover, local circumstances indicated the potential existence of stressed vegetation coexisting with evaporating soil, or substrate, which is a condition that cannot be modelled by TSEB1 nor TSEB2I.

Acknowledgments. The research leading to these results was funded by the European Community's 7th Framework Programme (FP7/2008-2013) under EUFAR contract No. 227159, Cost Action ES0903-EUROSPEC, and ESA Grant D/EOP/rp/2012/48. The work of Ana Andreu was partly supported by grant AGL2011-30498 (Ministerio de Economía y Competitividad of Spain, co-funded by FEDER).

We would like to thank Christiaan van der Tol, Wout Verhoef, and Zhongbo Su for their critical and helpful comments and suggestions. We also thank Jose Sobrino of the Global Change Unit at the Department of Earth 
Physics, University of Valencia, Spain, for providing the remote sensing data and Fernando de la Cruz of the Instituto Tecnico Agronomico Provincial de Albacete (ITAP), Spain, for the ground meteorological observations of the EODIX Campaign. We also would like to thank Bill Kustas for critically reviewing, which led to substantial improvement of this contribution.

\section{References}

Anderson, M.C., J.M. Norman, G.R. Diak, W.P. Kustas, and J.R. Mecikalski (1997), A two-source time-integrated model for estimating surface fluxes using thermal infrared remote sensing, Remote Sens. Environ. 60, 2, 195-216, DOI: $10.1016 / \mathrm{S} 0034-4257(96) 00215-5$.

Anton, J.A., and J.K. Ross (1987), Emissivity of the vegetation-soil system, Sov. J. Remote Sens. 5, $49-55$ (in Russian with English summary).

Brutsaert, W. (1982), Evaporation into the Atmosphere. Theory, History, and Applications, Springer Science \& Business Media, Dordrecht, DOI: 10.1007/ 978-94-017-1497-6, $299 \mathrm{pp}$.

Campbell, G.S., and J.M. Norman (eds.) (1998), An Introduction to Environmental Biophysics, 2nd ed., Springer, New York.

Choudhury, B.J. (1987), Relationships between vegetation indices, radiation absorption, and net photosynthesis evaluated by a sensitivity analysis, Remote Sens. Environ. 22, 2, 209-233, DOI: 10.1016/0034-4257(87)90059-9.

Choudhury, B.J., N.U. Ahmed, S.B. Idso, R.J. Reginato, and C.S.T. Daughtry (1994), Relations between evaporation coefficients and vegetation indices studied by model simulations, Remote Sens. Environ. 50, 1, 1-17, DOI: 10.1016/0034-4257(94)90090-6.

Colaizzi, P.D., W.P. Kustas, M.C. Anderson, N. Agam, J.A. Tolk, S.R. Evett, T.A. Howell, P.H. Gowda, and S.A. O'Shaughnessy (2012a), Two-source energy balance model estimates of evapotranspiration using component and composite surface temperatures, Adv. Water Resour. 50, 134-151, DOI: 10.1016/j.advwatres.2012.06.004.

Colaizzi, P.D., S.R. Evett, S.A. O'Shaughnessy, and T.A. Howell (2012b), Using plant canopy temperature to improve irrigated crop management. In: Proc. 24th Annual Central Plains Irrigation Conf., 21-22 February 2012, Colby, USA, 203-223.

Corbari, C., W. Timmermans, and A. Andreu (2015), Intercomparison of surface energy fluxes estimates from the FEST-EWB and TSEB models over the heterogeneous REFLEX 2012 site (Barrax, Spain), Acta Geophys. 63, 6, 16091638, DOI: $10.2478 / \mathrm{s} 11600-014-0258-\mathrm{x}$ (this issue).

de Miguel, E., M. Jiménez, I. Pérez, Ó.G. de la Camara., F. Muñoz, and J.A. Gómez-Sánchez (2015), AHS and CASI processing for the REFLEX 
remote sensing campaign: methods and results, Acta Geophys. 63, 6, 14851498, DOI: 10.1515/acgeo-2015-0031 (this issue).

French, A.N., F. Jacob, M.C. Anderson, W.P. Kustas , W. Timmermans, A. Gieske, Z. Su, H. Su, M.F. McCabe, F. Li, J. Prueger, and N. Brunsell (2005), Surface energy fluxes with the Advanced Spaceborne Thermal Emission and Reflection Radiometer (ASTER) at the Iowa 2002 SMACEX site (USA), Remote Sens. Environ. 99, 1-2, 55-65, DOI: 10.1016/j.rse.2005.05.015.

Gardner, B.R., D.C. Nielsen, and C.C. Shock (1992), Infrared thermometry and the Crop Water Stress Index. I. History, theory, and baselines, J. Prod. Agric. 5, 4, 462-466, DOI: 10.2134/jpa1992.0462.

Gillespie, A., S. Rokugawa, T. Matsunaga, J.S. Cothern, S. Hook, and A.B. Kahle (1998), A temperature and emissivity separation algorithm for Advanced Spaceborne Thermal Emission and Reflection Radiometer (ASTER) images, IEEE Trans. Geosci. Remote Sens. 36, 4, 1113-1126, DOI: 10.1109/ 36.700995 .

Gonzalez-Dugo, M.P., C.M.U. Neale, L. Mateos, W.P. Kustas, J.H. Prueger, M.C. Anderson, and F. Li (2009), A comparison of operational remote sensing-based models for estimating crop evapotranspiration, Agr. Forest Meteorol. 149, 11, 1843-1853, DOI: 10.1016/j.agrformet.2009.06.012.

Huntingford, C., S.J. Allen, and R.J. Harding (1995), An intercomparison of single and dual-source vegetation-atmosphere transfer models applied to transpiration from Sahelian savannah, Bound.-Lay. Meteorol. 74, 4, 397-418, DOI: 10.1007/BF00712380.

Jackson, R.D., S.B. Idso, R.J. Reginato, and P.J. Pinter Jr. (1981), Canopy temperature as a crop water stress indicator, Water Resour. Res. 17, 4, 1133-1138, DOI: 10.1029/WR017i004p01133.

Kalma, J.D., T.R. McVicar, and M.F. McCabe (2008), Estimating land surface evaporation: A review of methods using remotely sensed surface temperature, data, Surv. Geophys. 29, 4-5, 421-469, DOI: 10.1007/s10712-0089037-z.

Kustas, W.P., and J.M. Norman (1997), A two-source approach for estimating turbulent fluxes using multiple angle thermal infrared observations, Water Resour. Res. 33, 6, 1495-1508, DOI: 10.1029/97WR00704.

Kustas, W.P., and J.M. Norman (1999), Evaluation of soil and vegetation heat flux predictions using a simple two-source model with radiometric temperatures for partial canopy cover, Agr. Forest Meteorol. 94, 1, 13-29, DOI: 10.1016/S0168-1923(99)00005-2.

Kustas, W.P., and J.M. Norman (2000), A two-source energy balance approach using directional radiometric temperature observations for sparse canopy covered surfaces, Agron. J. 92, 5, 847-854, DOI: 10.2134/agronj2000.925847x.

Kustas, W.P., D.I. Stannard, and K.J. Allwine (1996), Variability in surface energy flux partitioning during Washita '92: Resulting effects on Penman- 
Monteith and Priestley-Taylor parameters, Agr. Forest Meteorol. 82, 1-4, 171-193, DOI: 10.1016/0168-1923(96)02334-9.

Kustas, W.P., X. Zhan, and T.J. Schmugge (1998), Combining optical and microwave remote sensing for mapping energy fluxes in a semiarid watershed, Remote Sens. Environ. 64, 2, 116-131, DOI: 10.1016/S0034-4257(97) 00176-4.

Lhomme, J.P., and A. Chehbouni (1999), Comments on dual-source vegetationatmosphere transfer models, Agr. Forest Meteorol. 94, 3-4, 269-273, DOI: 10.1016/S0168-1923(98)00109-9.

Li, F., W.P. Kustas, J.H. Prueger, C.M.U. Neale, and T.J. Jackson (2005), Utility of remote sensing-based two-source energy balance model under low- and high-vegetation cover conditions, J. Hydrometeor. 6, 6, 878-891, DOI: 10.1175/JHM464.1.

Massman, W.J., and J.C. Weil (1999), An analytical one-dimensional second-order closure model of turbulence statistics and the Lagrangian time scale within and above plant canopies of arbitrary structure, Bound.-Lay. Meteorol. 91, 1, 81-107, DOI: 10.1023/A:1001810204560.

Mattar, C., B. Franch, J.A. Sobrino, C. Corbari, J.C. Jiménez-Muñoz, L. OliveraGuerra, D. Skokovic, G. Sória, R. Oltra-Carriò, Y. Julien, and M. Mancini (2014), Impacts of the broadband albedo on actual evapotranspiration estimated by S-SEBI model over an agricultural area, Remote Sens. Environ. 147, 23-42, DOI: 10.1016/j.rse.2014.02.011.

Merlin, O., and A. Chehbouni (2004), Different approaches in estimating heat flux using dual angle observations of radiative surface temperature, Int. J. Remote Sens. 25, 1, 275-289, DOI: 10.1080/0143116031000116408.

Morillas, L., M. García, H. Nieto, L. Villagarcia, I. Sandholt, M.P. Gonzalez-Dugo, P.J. Zarco-Tejada, and F. Domingo (2013), Using radiometric surface temperature for surface energy flux estimation in Mediterranean drylands from a two-source perspective, Remote Sens. Environ. 136, 234-246, DOI: 10.1016/j.rse.2013.05.010.

Norman, J.M., W.P. Kustas, and K.S. Humes (1995), Source approach for estimating soil and vegetation energy fluxes in observations of directional radiometric surface temperature, Agr. Forest Meteorol. 77, 3-4, 263-293, DOI: 10.1016/ 0168-1923(95)02265-Y.

Priestley, C.H.B., and R.J. Taylor (1972), On the assessment of surface heat flux and evaporation using large-scale parameters, Mon. Weather Rev. 100, 2, 81-92, DOI: 10.1175/1520-0493(1972)100<0081:OTAOSH>2.3.CO;2.

Scott, R.L., T.E. Huxman, W.L. Cable, and W.E. Emmerich (2006), Partitioning of evapotranspiration and its relation to carbon dioxide exchange in a Chihuahuan Desert shrubland, Hydrol. Process. 20, 15, 3227-3243, DOI: 10.1002/ hyp. 6329. 
Shuttleworth, W.J., and R.J. Gurney (1990), The theoretical relationship between foliage temperature and canopy resistance in sparse crops, Quart. J. Roy. Meteorol. Soc. 116, 492, 497-519, DOI: 10.1002/qj.49711649213.

Sobrino, J.A., J.C. Jiménez-Muñoz, P.J. Zarco-Tejada, G. Sepulcre-Cantò, and E. de Miguel (2006), Land surface temperature derived from airborne hyperspectral scanner thermal infrared data, Remote Sens. Environ. 102, 1-2, 99-115, DOI: 10.1016/j.rse.2006.02.001.

Sobrino, J.A., J.C. Jiménez-Muñoz, P.J. Zarco-Tejada, G. Sepulcre-Cantó, E. de Miguel, G. Sòria, M. Romaguera, Y. Julien, J. Cuenca, V. Hidalgo, B. Franch, C. Mattar, L. Morales, A. Gillespie, D. Sabol, L. Balick, Z. Su, L. Jia, A. Gieske, W.J. Timmermans, A. Olioso, F. Nerry, L. Guanter, J. Moreno, and Q. Shen (2009), Thermal remote sensing from Airborne Hyperspectral Scanner data in the framework of the SPARC and SEN2FLEX projects: an overview, Hydrol. Earth Syst. Sci. 13, 2031-2037, DOI: 10.5194/hess-132031-2009.

Timmermans, J., C. van der Tol, W. Verhoef, and Z. Su (2008), Contact and directional radiative temperature measurements of sunlit and shaded land surface components during the SEN2FLEX 2005 campaign, Int. J. Remote Sens. 29, 17-18, 5183-5192, DOI: 10.1080/01431160802036599.

Timmermans, W.J., W.P. Kustas, M.C. Anderson, and A.N. French (2007), An intercomparison of the Surface Energy Balance Algorithm for Land (SEBAL) and the Two-Source Energy Balance (TSEB) modeling schemes, Remote Sens. Environ. 108, 4, 369-384, DOI: 10.1016/j.rse.2006.11.028.

Timmermans, W.J., G. Bertoldi, J.D. Albertson, A. Olioso, Z. Su, and A.S.M. Gieske (2008), Accounting for atmospheric boundary layer variability on flux estimation from RS observations, Int. J. Remote Sens. 29, 17-18, 52755290, DOI: 10.1080/01431160802036383.

Timmermans, W.J., Z. Su, and A. Olioso (2009), Footprint issues in scintillometry over heterogeneous landscapes, Hydrol. Earth Syst. Sci. 13, 2179-2190, DOI: 10.5194/hess-13-2179-2009.

Timmermans, W.J., J.C. Jiménez-Muñoz, V. Hidalgo, K. Richter, J.A. Sobrino, G. d'Urso, F. Mattia, G. Satalino, E. De Lathauwer, and V.R.N. Pauwels (2011), Estimation of the spatially distributed surface energy budget for AgriSAR 2006, Part I: Remote sensing model intercomparison, IEEE J. STARS 4, 2, 465-481, DOI: 10.1109/JSTARS.2010.2098019.

Timmermans, W.J., C. van der Tol, J. Timmermans, M. Ucer, X. Chen, L. Alonso, J. Moreno, A. Carrara, R. Lopez, F. de la Cruz Tercero, H.L. Corcoles, E. de Miguel, J.A.G. Sanchez, I. Pérez, B. Franch, J.-C.J. Munoz, D. Skokovic, J. Sobrino, G. Soria, A. MacArthur, L. Vescovo, I. Reusen, A. Andreu, A. Burkart, C. Cilia, S. Contreras, C. Corbari, J.F. Calleja, R. Guzinski, C. Hellmann, I. Herrmann, G. Kerr, A.-L. Lazar, B. Leutner, G. Mendiguren, S. Nasilowska, H. Nieto, J. Pachego-Labrador, S. Pulanekar, R. Raj, A. Schikling, B. Siegmann, S. von Bueren, and Z. Su (2015), An overview of the Regional Experiments for Land-atmosphere Exchanges 
2012 (REFLEX 2012) campaign, Acta Geophys. 63, 6, 1465-1484, DOI: 10.2478/s11600-014-0254-1 (this issue).

van der Tol, C., W. Timmermans, C. Corbari, A. Carrara, J. Timmermans, and Z. Su (2015), An analysis of turbulent heat fluxes and the energy balance during the REFLEX campaign, Acta Geophys. 63, 6, 1516-1539, DOI: 10.1515/ acgeo-2015-0061 (this issue).

Vesala, T., N. Kljun, U. Rannik, J. Rinne, A. Sogachev, T. Markkanen, K. Sabelfeld, T. Foken, and M.Y. Leclerc (2008), Flux and concentration footprint modelling: State of the art, Environ. Poll. 152, 3, 653-666, DOI: 10.1016/ j.envpol.2007.06.070.

Vining, R.C., and B.L. Blad (1992), Estimation of sensible heat flux from remotely sensed canopy temperatures, J. Geophys. Res. 97, D17, 18951-18954, DOI: 10.1029/92JD01626.

Received 27 June 2014

Received in revised form 27 February 2015

Accepted 10 April 2015 